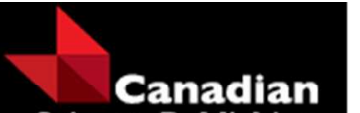

Science Publishing

Canadian Journal of Forest Research

Revue canadienne de recherche forestière

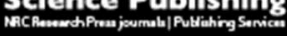

\title{
Physiological responses to alternative flooding and drought stress episodes in two willow (Salix spp.) clones.
}

\begin{tabular}{|r|l|}
\hline Journal: & Canadian Journal of Forest Research \\
\hline Manuscript ID & cjfr-2016-0202.R1 \\
\hline Manuscript Type: & Article \\
\hline Date Submitted by the Author: & $29-$ Sep-2016 \\
\hline Complete List of Authors: & $\begin{array}{l}\text { Doffo, Guillermo; Instituto de Fisiologia Vegetal } \\
\text { Monteoliva, Silvia; Universidad Nacional de La Plata, Facultad de Cencias } \\
\text { Agrarias y Forestales } \\
\text { Rodríguez, Maria; Instituto de Fisiologia Vegetal } \\
\text { Luquez, Virginia; Instituto de Fisiologia Vegetal }\end{array}$ \\
\hline Keyword: & $\begin{array}{l}\text { water stress, hydraulic conductivity, vessel, stomatal conductance, root to } \\
\text { shoot ratio }\end{array}$ \\
\hline &
\end{tabular}

SCHOLARONE $^{\text {m }}$

Manuscripts 
1

2

3

4

5

6

7

8

9

10

11

12

13

14

15

16 1: guilledoffo@gmail.com

17 2: smonteoliva@yahoo.com.ar

18 3: emiliar21@gmail.com

19

20

21

22

23

24

25 willow (Salix spp.) clones.

Guillermo N. Doffo ${ }^{1}$, Silvia E. Monteoliva ${ }^{2}$, María E. Rodríguez ${ }^{4}$, Virginia M.C. Luquez ${ }^{4}$.

Instituto de Fisiología Vegetal (INFIVE), UNLP - CONICET, FCAyF UNLP, CC 327, 1900 La Plata, Argentina.

4: Author for correspondence. vluquez@agro.unlp.edu.ar. Tel: +54-221-423-6618.

FAX: +54-221-423-3698. 


\section{Abstract}

Climate change will increase the occurrence of flash floods as a consequence of extreme rain events, creating alternate periods of drought and flooding during the growing season. We analyzed the responses of two willow clones with contrasting responses to flooding (clone B: Salix matsudana x Salix alba hybrid; clone Y: Salix alba) to different combinations of stress treatments: continuous flooding or drought for six weeks, or cyclic treatments of two weeks of stress separated by two weeks of watering at field capacity. Drought reduced growth, stomatal conductance and total leaf area in both clones, but flooding did not. Flooding reduced the root/shoot ratio in both clones. The hydraulic conductivity of the main stem was significantly reduced by drought only in clone $\mathrm{Y}$. The area of the vessels was decreased by both drought and flooding, but the number was increased only by drought. The occurrence of drought before flooding reduced the vessel area, but the opposite treatment did not. An episode of drought after one of flooding is more stressful than the opposite situation, especially for clone $Y$ that could not adjust its water transport capacity during the drought period.

3 Key words: water stress, hydraulic conductivity, vessels, stomatal conductance, root to shoot ratio 


\section{Introduction}

Climate change will increase the occurrence of flooding episodes in several areas of the world (Kreuswieser and Rennenberg 2014, Cavalcanti et al. 2015). The riparian zones are particularly susceptible to an increased risk of flooding and drought under climate change, causing modifications in plant community composition and species richness (Garssen et al. 2014, Garssen et al. 2015). Willows (Salix spp.) can colonize and grow successfully on areas periodically disturbed by flooding, like floodplains (Karrenberg et al. 2002) and tidal wetlands (Markus-Michalczyk et al. 2016 a). In consequence, willows are natural candidates for developing forest plantations in flood prone areas that are marginal for agriculture. There is an increased demand for forest-derived products for different uses, including the supply of biomass for energy production. To fulfill this demand, willow plantations are being developed in areas that can experience alternate short periods of drought and flash flooding during the growing season. To improve the success of plantations in disturbed areas, it is necessary to gain a better understanding of the physiological responses of willows growing under these particular combinations of environmental stresses.

Willow responses to drought and flooding have been previously analyzed separately, and the responses are different according to the genotype and the duration of the stress episode (Li et al 2004, Wikberg and Ögren 2004). It has been shown that willow responses to continuous drought are different from those under cyclic drought (Bonosi et al. 2010). Meanwhile, the responses of different tree species to a flooding event may vary if they suffered from a previous episode of flooding. In poplars, the occurrence of a pre-conditioning flooding period improved waterlogging tolerance (Bejaoui et al. 2012). In willows, the combination of drought and flooding has been addressed to a lesser extent than both stresses separately (Nakai et al. 2010, Nakai and Kisanuki 2011). Some morphological responses to drought are the opposite of those to flooding. For instance, drought increases the root/shoot ratio while flooding reduces it (Kozlowzki 1997, Markus-Michalczyk et al. 2016 b). In this context, a previous episode of flooding that reduced root biomass could be detrimental for a plant experiencing drought later. It has been shown that drought 
74 susceptibility in willows is related to their vulnerability to cavitation (Wikberg and Ögren 2007, 75 Savage and Cavender-Bares 2011, Ogasa et al. 2013). Flooding can alter water transport in 76 tropical trees (Herrera et al. 2008), and reduce vessel size and hydraulic conductivity in

77 Quercus robur (Copini et al. 2016). But nothing is known about the effects of a combination 78 of both stresses on the hydraulic conductivity of willows.

The aim of this work is to analyze the responses of two willow clones to drought, 80 flooding and the alternation of these stresses. In a previous work, we identified willow genotypes with contrasting tolerance to flooding (Cerrillo et al. 2013). We expect that these

82 clones will modify their physiology in different ways to acclimate to drought, flooding and the alternative ocurrence of these stresses.

We hypothesize that: 1 - The clones will differ in their tolerance to the alternation of drought and flooding stress; and 2 - The order of occurrence of drought and flooding episodes will modify the growth, water transport capacity, xylem anatomy, gas exchange and leaf area dynamics of willows in different ways.

\section{Materials and Methods}

Plant material and growth conditions

The clones used in this work were obtained in a breeding program from INTA (Instituto Nacional de Tecnología Agropecuaria, Argentina), they were a hybrid Salix matsudana x Salix alba "Barrett 13-44 INTA" (clone B); and an open pollinated S. alba clone, "Yaguareté INTA CIEF" (clone Y). Clone B showed susceptibility to long periods of flooding in the field (Cerrillo et al. 2013), while clone $Y$ was more tolerant to flooding in such conditions (T. Cerrillo, personal communication). Both clones have a similar sprouting date, making growth comparisons straightforward.

One-year-old cuttings of $20 \mathrm{~cm}$ length were planted in $4.5 \mathrm{~L}$ pots filled with a $1: 1$ sand/soil mixture in a greenhouse in the city of La Plata, Argentina ( $\left.34^{\circ} 54^{\prime} \mathrm{S}\right)$. The 
101 maximum irradiance at midday was $1600 \mu$ moles photons $\mathrm{m}^{-2} \mathrm{~s}^{-1}$. There was no

102 supplemental artificial light added to increase the irradiance or alter the natural photoperiod.

103 The planting date was August $13^{\text {th }}, 2012$, and one cutting per pot was planted. The

104 pots were placed in a randomized design with 6 replicates for each clone and treatment

105 level. The plants were surrounded by a border row that was not used for measurements.

106 Plants were watered to keep the soil at field capacity (FC) until the beginning of the stress

107 treatment. Bud flush occurred in both clones between August $30^{\text {th }}$ and September $4^{\text {th }}$. After

108 sprouting and before starting the treatment, $50 \mathrm{ml}$ of complete Hoagland solution was added

109 weekly to the pots to ensure an adequate nutrient availability. To avoid pests, the trees were

110 treated every two weeks with an insecticide (o,s dimethyl-acethyl phosphoroamydotiathe).

111 Before the beginning of the treatment, cuttings were pruned and only one shoot was kept, in

112 order to minimize the variability induced by different number of shoots per tree. Flooding was

113 induced by placing the pots with the trees into a sealed $7 \mathrm{~L}$ pot filled with tap water up to

114 approximately $10 \mathrm{~cm}$ above soil level; water was added when necessary to keep this level.

115 Drought was induced by watering the plants with $50 \mathrm{ml}$ of water every other day.

116 The stress treatment started on October $31^{\text {th }}, 2012$, and the different combinations

117 were applied as follows: 1 - watered to field capacity (FC); 2 - six weeks of continuous

118 drought (Drought); 3 - two weeks of drought, two weeks watered to field capacity, two weeks

119 of drought (D-FC-D); 4 - two weeks of drought, two weeks watered to field capacity, two

120 weeks of flooding (D-FC-F); 5 - two weeks of flooding, two weeks watered to field capacity,

121 two weeks of drought (F-FC-D); 6 - two weeks of flooding, two weeks watered to field

122 capacity, two weeks of flooding (F-FC-F) ; 7 - six weeks of continuous flooding (Flooding).

123 The period of watering at field capacity was included because it is possible to go from

124 drought to flooding immediately, but not the other way around, because after flooding the soil

125 will be saturated for several days, even without any watering.

126

127 Growth, water consumption and gas exchange measurements 
Total shoot height $(\mathrm{cm})$ was measured once a week with a graduate stick. At the beginning of the experiment, the last completely expanded leaf was tagged with a color wire, and all leaves below this mark were counted every week, providing a measurement of the abscission of basal leaves in each treatment.

Stomatal conductance was measured on seven different dates with a Decagon SC1 porometer on the abaxial side of the latest fully expanded leaf. The measurements were carried out on cloudless days without any artificial light supplements, between 11.30 am and $01.30 \mathrm{pm}$, and the average irradiance during those measurements was $1150 \mu$ moles $\mathrm{m}^{-2} \mathrm{~s}^{-1}$. Six repetitions were measured for each clone and treatment.

The dry weight of leaves, stems and roots was determined at the end of the experiment, after drying them at $65^{\circ} \mathrm{C}$ to constant weight. The total leaf area $\left(\mathrm{cm}^{2}\right)$ was measured at the end of the experiment by scanning the leaves and determining their area using the software IMAGE J (http://rsbweb.nih.gov/ij/, Schneider et al. 2012).

The water consumption (WC) of the whole plant was estimated as follows: Two days before the end of the experiment, the pots were sealed with a double plastic bag, and weighted. The last day, they were weighted again and the difference in weight gave an estimation of the water consumed by the plant.

Hydraulic conductivity measurements

Hydraulic conductivity was measured in four plants of each clone and treatment at the end of the experiment. Measurements were taken on the stem segment immediately above

149 the latest expanded leaf at the beginning of the experiment. This part of the stem was 150 selected because it was still growing, and would eventually reflect changes due to the 151 stresses imposed. In the early morning, shoots were cut under water and taken to the 152 laboratory in water buckets and kept in water until measurements were performed that same 153 day. The stem segment to be measured was re-cut under water, and connected to the 154 hydraulic head. Degassed and deionized water was perfused through one of the ends of the 155 segments. The pressure gradient was $0.011 \mathrm{MPa}$, and in this situation, the embolisms (if 
156 present) were not removed. When the flux achieved a steady state, the water extruding from

157 the segments was collected in a pre-weighted tube. The time spent on water collection was 158 also measured (minimum 13 minutes, maximum 58 minutes). The water flux was estimated 159 by weighing the tubes on a digital balance. For the measurements, the segments were 160 decorticated. The total length of the segments and the diameter of both extremes were 161 measured with a digital caliper, and the xylem area was calculated with the mean of both 162 diameters; the pith area was not subtracted because the whole decorticated area was 163 conductive. The values of the hydraulic conductivity per unit stem length (kh), the specific 164 hydraulic conductivity per unit of xylem area (ks) and the specific hydraulic conductivity per 165 unit leaf area $(\mathrm{kl})$ were calculated according to the modified Poiseuille's law (Cruiziat et al. 166 2002).

Anatomical analysis

The anatomical analysis was carried out on the same stem segment used to measure the hydraulic conductivity. To determine wood anatomy, the entire cross-sections $(20 \mu \mathrm{m})$ of

171 stem segments were cut using a sliding microtome, then stained in safranin (1\%),

172 dehydrated, and mounted in Entellan® for microscopic analysis. Images were captured with 173 a digital camera (Olympus DP71) mounted on a research microscope (Olympus BX50, 174 Japan). The captured images were analyzed for the following parameters, using the image 175 analysis software to count/size and measure objects ImagePro Plus v. 6.3, Media

176 Cybernetics USA: vessel lumen diameter $(\mu \mathrm{m})$, vessel area $\left(\mathrm{AV}, \mu \mathrm{m}^{2}\right)$ and vessel number $177\left(\mathrm{NV}, \mathrm{n}^{\circ} / \mathrm{mm}^{2}\right)$.

Statistical Analysis

Most data did not meet the ANOVA assumptions of normality and equality of 181 variance, and this could not be improved by data transformation. In consequence, the 182 Kruskal-Wallis rank sum test was used for the analysis. The statistical analysis was carried 
183 out with the R software 3.2.2 (R Core Team, 2015) using the package agricolae version 1.2-3

184 for the Kruskal-Wallis test.

185 For the Principal Components Analysis (PCA), the data were centered and 186 standardized. The variables included in the PCA were: RSR (root to shoot ratio); NV (number 187 of vessels); AV (area of vessels); kh (hydraulic conductivity per unit stem length), ks 188 (hydraulic conductivity per unit of xylem area); kl (hydraulic conductivity per unit leaf area), 189 NBL (number of basal leaves); WC (water consumption); TLA (total leaf area); TDW (total dry 190 weight); Hf (final height, day 41); gs (stomatal conductance measured on day 41).

\section{Results}

194 Gas exchange measurements

195 During the flooding periods, there were no significant differences in stomatal conductance (gs, Fig.1) between control and flooded plants of clone Y. In some dates, gs was significantly reduced in flooded plants of clone B compared to control treatment. However, gs was reduced during the drought periods in all treatments including drought in both clones. The reduction was more pronounced in the permanent drought treatment, whereas in the cyclic drought treatments, gs recovered to the levels of controls when plants were watered to field capacity. These results show that the treatments were effective at inducing drought stress in the willow clones. Growth in height showed the same pattern, being reduced only in the drought treatments (Supplementary Fig.1).

\section{Growth measurements}

The number of basal leaves indicate the occurrence of leaf area adjustment through leaf abscission (Fig. 2). Leaf shedding was scarce on control and flooded plants, while abscission was enhanced by drought in both clones, causing the reduction in total leaf area at the end of the experiment (Supplementary Fig.2). In the F-FC-D and D-FC-F treatment, 
211 basal leaves for the cyclic drought treatments was more pronounced in clone $Y$ than in clone 212 B

213 Total dry weight (Fig.3) was significantly reduced compared to controls under 214 continuous drought, D-FC-D, and F-FC-D. In D-FC-F treatment, the reduction was significant 215 only for clone Y. Continuous flooding and F-FC-F did not reduce the total dry weight in either 216 of the clones.

217 In spite of the similar value of total dry weight in control plants, the dry matter 218 partitioning was different in both clones. Clone B invested more in roots than clone $\mathrm{Y}$, and 219 consequently had a significantly higher RSR (Fig. 3). Both clones significantly reduced RSR 220 under flooding, applied either in the continuous (Flooding) or cyclic form (F-FC-F). In the 221 other treatments, there were no statistically significant differences in root/shoot ratio 222 compared to control plants.

Hydraulic conductivity and xylem anatomy

The hydraulic conductivity measured as kh, ks or kl (Fig. 4) was similar in the control 226 plants of clone $B$ and $Y$. All three parameters were reduced in the D-FC-D and F-FC-D treatments, but these differences were statistically significant only in clone $\mathrm{Y}$.

The gs / ks ratio (Table 1) was calculated using the values of gs at the end of the experiment. This ratio gives an insight of the capacity to maintain water balance under 230 drought stress (Wikberg and Ögren 2007). Clone B significantly reduced this ratio for

231 drought, F-FC-D and D-FC-D treatments, while in clone $\mathrm{Y}$ the reduction was only significant 232 in D-FC-D.

233 The area $(\mathrm{AV})$ and number of vessels per $\mathrm{mm}^{2}(\mathrm{NV})$ were measured in the same 234 stem segment used to determine hydraulic conductivity (Fig. 5). The response of the 235 diameter and area of the vessels to the different treatments was similar, in consequence only 236 the area data is shown. In field capacity plants, clone B had a higher NV and of a smaller 237 size than those of clone $\mathrm{Y}$, but the differences were significant only for the number. In clone 238 B, NV increased significantly only under continuous drought, while there were no differences 
in the other treatments. In clone $\mathrm{Y}, \mathrm{NV}$ increased significantly in drought, D-FC-D, D-FC-F and F-FC-F compared to controls, while there were no changes in F-FC-D and flooding treatments (Fig. 5, and S.Fig.3). AV decreased significantly in treatments drought, D-FC-D, D-FC-F and flooding in clone B, while there were no differences in F-FC-D and F-FC-F. In clone $\mathrm{Y}, \mathrm{AV}$ was significantly reduced in the drought, D-FC-D, D-FC-F, F-FC-F and flooding treatments, and did not change in F-FC-D (Fig. 5).

We carried out a PCA analysis to explore the relationship between the variables measured in the different combinations of treatments (Fig. 6). For variables measured several times (gs, height and number of leaves), only the last measurement of the experiment was included in the analysis because they could be compared with the other variables measured at the end of the experiment. The first and second components together explained $78 \%$ of the total variation. The variables WC, gs, NBL and TLA superposed with each other, lying within the first component. The root to shoot ratio (RSR) had a negative correlation with height $(\mathrm{Hf})$ and total dry weight $(\mathrm{TDW})$. The area and number of vessels (AV and NV) had the opposite tendency: one increased while the other decreased.

\section{Discussion}

Drought and flooding caused different degree of stress in willows.

From our results, it is clear that flooding is a less stressful situation than drought for willows, because the flooded plants differ less from the field capacity treatment. This is clearly reflected in the PCA analysis, where the treatments are divided in two main groups along the first component. One group includes the drought treatments (drought, D-FC-D and F-FC-D); and the other group includes the FC, Flooding, F-FC-F and D-FC-F treatments. The reason is that several growth and physiological variables were reduced by drought compared to the field capacity treatment (gs, WC, TLA, TDW, NBL), but this did not happen with flooding. The treatments including both drought and flooding (D-FC-F and F-FC-D) grouped closer to the last treatment than to the first one. The second component of the PCA analysis 
267 mainly reflected differences at clone level. This axis separated the clones because several of

268 the variables shared were different from the beginning, or because they had different 269 responses to the stress episodes (NV, AV, height, RSR, kl, ks).

270

271 Flooding and drought caused different effects on willows growth.

272 The main differences between treatments occurred in biomass accumulation and 273 partition between plant organs. Flooding did not reduce TDW in any of the clones, while 274 drought -continuous or cyclic- decreased it. In spite of having a similar total dry weight under 275 well-watered conditions, the dry matter partitioning was different in both clones. Clone B 276 allocated more biomass to the root system, whereas clone $Y$ did so in the stem, resulting in 277 differences in RSR. Under F and FCF treatments RSR was reduced in both clones compared 278 to control plants, these results are similar to those of Salix alba where repeated flooding 279 reduced root biomass (Markus-Michalczyk et al. 2016 b).

280 In D, D-FC-D, F-FC-D and D-FC-F treatments, the RSR did not differ significantly 281 compared to field capacity (Fig.3). This result was similar to the one described previously for 282 Salix gracylistila, where RSR was similar in control and drought-stressed plants (Nakai et al. 283 2010). The lack of a significant increase in RSR could be a factor increasing drought 284 susceptibility of willows compared with other forest trees. An increased allocation of biomass 285 to roots allows the exploration of a higher volume of soil, improving water extraction under 286 drought conditions, but this response did not occur in our clones. In addition, it has been 287 suggested that in Salix gracilistyla, a period of flooding sensitized plants to subsequent 288 drought because of root damage (Nakai and Kisanuki 2011).

289 The growth measurements closely correlate with total leaf area. Leaf area reduction is 290 a mechanism to diminish the water consumption of the whole plant when the water supply is 291 limited (Savage et al. 2009, Bonosi et al. 2010). Salix species tend to experience extensive 292 defoliation under drought, and it has been proposed that it is a mechanism to confine 293 embolism to petioles and leaves (Savage and Cavender-Bares 2011). The D and FCD 294 treatments showed the stronger reduction in leaf area due to leaf abscission. The reduction 
in leaf area is not the only mechanism to reduce transpiration; stomatal closure is clearly

296

297

298

299

300

301

302

303

304

305

306

307

308

309

310

311

312

313

314

315

316

317

318

319

320

321

322

relevant to the control of water loss in plants under drought, as Fig.1 shows. This fact is highlighted by the coincidence of TLA, gs and WC in the first component of the PCA analysis. This can explain why plants of the F-FC-D treatment experienced a sharper decline in gs and leaf abscission (NBL) in the drought period compared with the D-FC-F treatment (Fig. 1 and 2).

The order of occurrence of drought and flooding episodes caused different acclimation responses of water transport capacity in willows.

Drought, flooding and drought followed by flooding caused a significant reduction in vessel size compared to non-stressed plants, but flooding followed by drought did not.

The reduction in xylem vessel size and the increase in vessel number are welldocumented drought responses in several species, including Populus (Fichot el al. 2009). Smaller vessels in general have higher resistance to embolism, increasing drought tolerance. This development is not surprising, since drought resistance correlates with sensitivity to xylem cavitation in willows (Wikberg and Ögren 2004, Ogasa et al. 2013). We found a reduction in $\mathrm{AV}$ and an increase in NV in drought and D-FC-D treatments, indicating that both clones can acclimate to drought stress. Vessel size was reduced in the flooding treatment, but without a significant increase in NV (Fig. 5). This fact could explain the lower hydraulic conductivity observed in the same treatment, albeit it is not statistically significant (Fig.4). The smaller vessel area in flooded plants may indicate an adaptation to a reduction in water uptake caused by flooding, as found in Quercus robur (Copini et al. 2016). In Campsiandra laurifolia, there was a reduction in hydraulic conductivity in the first stages of seasonal flooding, but this fact was reversed later in the season (Herrera et al. 2008).

The D-FC-F treatment caused a reduction in vessel size in both clones, but in the FFC-D treatment the vessel area was not reduced. Since both drought and flooding alone caused a reduction in vessel area, the results in F-FC-D are surprising. Clearly, the order of occurrence of the stresses caused different responses in this trait. In F-FC-D treatment, 
323 clone B experienced a $50 \%$ drop in $\mathrm{kl}$ compared to field capacity treatment but in clone $\mathrm{Y}, \mathrm{kl}$

324 was decreased to $10 \%$ compared with the same treatment. The reduction in hydraulic 325 conductivity can be due to loss of vessel functionality through embolism or the reduction in 326 vessel size or number in the xylem formed during the stress. Clone B demonstrated a 327 reduced gs / ks ratio under the F-FD-D treatment, while clone $\mathrm{Y}$ was unaffected (Table 1). 328 This effect occurs only in F-FC-D treatment, while the other drought treatments clone $\mathrm{Y}$ can 329 reduce the gs / ks ratio, as other willows species do to acclimate to moderate drought 330 (Wikberg and Ögren 2007). This difference in response may be due to clone $Y$ having an 331 increased sensitivity to embolism. The cause for the greater sensibility to embolism in clone

$332 Y$ is probably the lack of reduction of vessel size, although other reasons cannot be 333 discarded. It has been suggested that the vulnerability to cavitation in poplars is related to 334 the porosity of the vessel pit membrane (Fichot et al. 2015); accordingly this or other xylem 335 traits are responsible for the higher susceptibility of clone $\mathrm{Y}$ to embolism.

The clones had contrasting responses to flooding and drought.

338 In a revision evaluating stress tolerance in 806 tree and shrubs species, a negative 339 correlation has been found between drought and waterlogging tolerance, implying a trade-off 340 between tolerance to these stresses (Niinemeets and Valladares 2006). Our results seem to 341 be in line with the hypothesis of a trade - off between drought and flooding tolerance. The 342 flood tolerant clone $Y$ was more drought sensitive, experiencing extensive defoliation and a 343 steep reduction of its water transport capacity under water shortage. On the other hand, flood 344 sensitive clone B (Cerrillo et al. 2013) retained a greater water transport capacity under 345 drought stress. It has been proposed that there are two possible strategies to cope with 346 drought in tree saplings: a low resistance to cavitation combined with lack of osmotic 347 adjustment and high abscission rate (desiccation avoidance), and a higher resistance to 348 cavitation combined with osmotic adjustment and leaf area retention (desiccation tolerance, 349 Yazaki et al. 2010). Willows seem to fit in the first strategy, because they are more sensitive 350 to cavitation than other tree species (Savage and Cavender-Bares 2011, Ogasa et al. 2013) 
351 and experience extensive defoliation under drought (Savage et al. 2009, Bonosi et al. 2010).

352 Both clones can reduce leaf area and gs under drought, but this is not enough to prevent 353 embolism in clone Y. In several temperate species, including Salix, a low cavitation 354 resistance is compensated by a higher recovery capacity through vessel refilling (Ogasa et 355 al. 2013). It is possible that clone $Y$ has a reduced capacity to repair embolism, while clone $B$ 356 is more efficient refilling the vessels and maintaining its water transport capacity under

357 drought. The architecture of clone B, with more biomass allocated to roots than shoot also 358 helps this clone to cope with water shortage. On the other hand, clone $\mathrm{Y}$ has a lower root to 359 shoot ratio, and this could explain the higher growth in height of this clone under field 360 capacity or waterlogged conditions.

Conclusion

363 Our first hypothesis stated that the clones will differ in their tolerance to the alternation 364 of drought and flooding stress. It proved correct for the F-FC-D treatment, since clone B was 365 more tolerant than clone $\mathrm{Y}$ under this treatment, while there was no difference between the 366 clones in the D-FC-F treatment. Regarding the second hypothesis, water transport capacity, 367 xylem anatomy and leaf area dynamics were affected in different ways in F-FC-D and D-FC-

368 F treatments. For willows, the occurrence of a drought episode after one of flooding is more 369 stressful than the opposite situation, especially for clone $Y$ that is not able to adjust its water 370 transport capacity during the drought period.

\section{Acknowledgements}

374 Thanks to C. Graciano for the critical reading of the manuscript, to M .G. Cano for the 375 technical assistance, and T. Cerrillo for providing clone Y. VMCL and SM are researchers

376 from CONICET. GND and MER held fellowships from CONICET. This work was funded by 377 PIA 10007- IBRD 7520 AR, Ministry of Agroindustry, Argentina, to VMCL. 


\section{References}

Béjaoui, Z., Albouchi, A., Lamhamedi, M.S., Abassi, M. and El Aouni, M.H. 2012. Adaptation and morpho-physiology of three Populus deltoides Marsh x Populus nigra L. clones after preconditioning to prolonged waterlogging. Agroforest Syst 86: 433 - 442.

Bonosi, L,, Ghelardini, L., and Weih, M. 2010. Growth responses of 15 Salix genotypes to temporary water stress are different from the responses to permanent water shortage. Trees 24: $843-854$.

Cavalcanti, I.F.A., Carril, A.F., Peñalba, O,C,, Grimm, A.M., Menéndez, C.G., Sánchez, E., Cherchi, A,, Sörensson, A., Robledo, F., Rivera, J., Pántano, V., Betolli, L.M., Zaninelli, P., Zamboni, L., Tedeschi, R.G., Domínguez, M., Ruscica, and R., Flach, R. 2015. Precipitation extremes over La Plata Basin. Review and new results from observations and climate simulations. J Hydrol 523: 211-230.

Cerrillo, T., Rodríguez, M.E., Achinelli, F., Doffo, G., and Luquez, V.M.C. 2013. Do greenhouse experiments predict willow responses to long-term flooding events in the field? Bosque 34: 71-79.

Copini, P., den Ouden J., Robert E., Tardif J.C., Loesberg W., Goudzwaard L., and SassKlassen U. 2016. Flood-ring formation and root development in response to experimental flooding in young Quercus robur trees. Frontiers Plant Sci 7-775. doi: 10.3389/fpls.2016.00775. 
Cruiziat, P., Cochard, H., and Améglio, T. 2002. Hydraulic architecture of trees: main concepts and results. Ann For Sci 59: 723-752.

Fichot, R., Laurans, F., Monclus, R., Moreau, A., Pilate, G., and Brignolas, F. 2009 Xylem anatomy correlates with gas exchange, water use efficiency and growth performance under contrasting water regimes: evidence from Populus deltoides x Populus nigra hybrids. Tree Physiol 29: 1537-1549.

Fichot, R., Brignolas, F., Cochard, H., and Ceulemans, R. 2015. Vulnerability to droughtinduced cavitation in poplars: synthesis and future opportunities. Plant Cell \& Environm 38: $1233-1251$.

Garssen, A., Verhoeven, J.T.A, and Soons, M. 2014. Effects of climate induced summer drought on riparian plant species: a meta-analysis. Freshwater Biol 59: 1052-1063.

Garssen, A., Baatrup-Pedersen, A., Voesenek, L.A.C.J., Verhoeven, J.T.A, and Soons, M. 2015. Riparian plant community responses to increased flooding: a meta-analysis. Global Change Biol 21: 2881-2890, doi: 10.1111/gcb.12921.

Herrera, A., Tezara, W., Rengifo, E., and Flores, S. 2008. Changes with seasonal flooding in sap flow of the tropical flood-tolerant tree species, Campsiandra laurifolia. Trees 22: 551 558.

Karrenberg, S., Edwards, P.J., Kollmann, J. 2002. The life history of Salicaceae living in the active zone of floodplains. Freshwater Biol 47: 733-748. 
Kozlowski, T.T. 1997. Responses of woody plants to flooding and salinity. Tree Physiology Monograph No 1 [online].Available from http://www.pucrs.br/fabio/fisiovegetal/Encharcamento.pdf. [Accesed 3 December 2015].

Kreuzwieser J., and Rennenberg H. 2014. Molecular and physiological responses of trees to waterlogging stress. Plant Cell Environ 37: 2245 - 2259.

Li, S., Pezeshki, S.R., Goodwin, S., and Shields, F.D. 2004. Physiological responses of black willow (Salix nigra) cuttings to a range of soil moisture regimes. Photosynthetica 42: 585-590.

Markus - Michalczyk H., Hanelt D., and Jensen K. 2016 a. Effects of tidal flooding on juvenile willows. Estuaries and Coasts 39:397-405

Markus - Michalczyk H., Hanelt D., Denstorf J., and Jensen K. 2016 b. White willow sexual regeneration under estuarine conditions in times of climate change. Estuarine Coastal Shelf Sci 180: 51-58.

Nakai, A., Yurugi, Y., and Kisanuki, H. 2010. Stress responses in Salix gracilistyla cuttings subjected to repetitive alternate flooding and drought. Trees 24: 1087 - 1095.

Nakai, A., and Kisanuki, H. 2011. Stress responses of Salix gracilistyla and Salix subfragilis cuttings to repeated flooding and drought. J For Res 16: 465-472.

Niinemets, Û., and Valladares, F. 2006. Tolerance to shade, drought and waterlogging of temperate Northern Hemisphere trees and shrubs. Ecol Monographs 76 (4) 521-547. 
Ogasa, M., Miki, N.H., Murakami,Y., and Yoshikawa, K. 2013. Recovery performance in xylem hydraulic conductivity is correlated with cavitation resistance for temperate deciduous tree species. Tree Physiol 33: 335-344.

R Core Team. 2015. R: A language and environment for statistical computing. R Foundation for Statistical Computing, Vienna, Austria. ISBN 3-900051-07-0. [online]. Available in http://www.R-project.org. [Accessed 18 October 2015].

Savage, J., Cavender Bares, J., and Verhoeven, A. 2009. Willow species (genus: Salix) with contrasting habitat affinities differ in their photo-protective responses to water stress. Func Plant Biol 36: 300-309.

Savage, J.A., and Cavender-Bares, J.M. 2011. Contrasting drought survival strategies of sympatric willows (genus: Salix): consequences for coexistence and habitat specialization. Tree Phys 31: 604-614.

Schneider, C.A., Rasband, W.S., and Eliceiri, K.W. 2012. NIH image to Image J: 25 years of image analysis. Nature Methods 9 (7) 671-675.

Wikberg, J., and Ögren, E. 2004. Interrelationships between water use and growth traits in biomass-producing willows. Trees 18: $70-76$.

Wikberg, J., and Ögren, E. 2007. Variation in drought resistance, drought acclimation and water conservation in four willows cultivars used for biomass production. Tree Physiol 27: $1339-1346$. 
Yazaki, K., Sano, Y., Fujikawa, S., Nakano, T., and Ishida, A. 2010. Responses to dehydration and irrigation in invasive and native saplings: osmotic adjustment versus leaf shedding. Tree Phys 30: $597-607$. 
Table 1 Ratio between stomatal conductance (gs, mmoles $\mathrm{m}^{-2} \mathrm{~s}^{-1}$ ) and hydraulic conductivity per unit xylem area (ks, $\mathrm{g} \mathrm{H}_{2} \mathrm{O} \mathrm{m} \mathrm{MPa}^{-1} \mathrm{~s}^{-1} \mathrm{~m}^{-2}$ ) under Field Capacity, Drought, D-FC-D, DFC-F, F-FC-D, F-FC-F and Flooding, at the end of the experiment. Mean values: plus minus one standard error of the mean. Treatments followed by the same letter did not differ according to the Kruskal-Wallis test $(p \leq 0.05)$.

\begin{tabular}{|l|ccl|}
\hline Treatment & Clone $\boldsymbol{B}$ & Clone & $\boldsymbol{Y}$ \\
\hline Field Capacity $(F C)$ & $0.31 \pm 0.08 \mathrm{bcd}$ & $0.49 \pm 0.18 \mathrm{abc}$ \\
Drought $(D)$ & $0.07 \pm 0.03 \mathrm{ef}$ & $0.22 \pm 0.05 \mathrm{cdef}$ \\
D-FC-D & $0.06 \pm 0.02 \mathrm{ef}$ & $0.14 \pm 0.07 \mathrm{def}$ \\
D-FC-F & $0.52 \pm 0.12 \mathrm{ab}$ & $0.61 \pm 0.06 \mathrm{a}$ \\
F-FC-D & $0.07 \pm 0.05 \mathrm{f}$ & $0.43 \pm 0.16 \mathrm{abc}$ \\
F-FC-F & $0.27 \pm 0.08 \mathrm{bcd}$ & $0.66 \pm 0.02 \mathrm{a}$ \\
Flooding $(F)$ & $0.24 \pm 0.02 \mathrm{bcde}$ & $0.84 \pm 0.32 \mathrm{a}$ \\
\hline
\end{tabular}




\section{Legends to the figures}

Fig. 1 Stomatal conductance (gs) of plants of two willow clones growing under different water regimes and their combinations. FC: field capacity. Vertical bars: standard error of the mean. Means marked with an asterisk differ significantly from the field capacity treatment on the same date according to the Kruskal-Wallis test $(p \leq 0.05)$.

Fig. 2 Number of basal leaves (leaves completely expanded at the beginning of the experiment) of plants of two willow clones growing under different water regimes and their combinations. FC: field capacity. Vertical bars: standard error of the mean. Means marked with an asterisk differ significantly from the field capacity treatment on the same date according to the Kruskal-Wallis test $(p \leq 0.05)$.

Fig. 3 Dry matter partitioning in plants of two willow clones growing under different water regimes and their combinations: FC (field capacity), F (flooding) and D (drought). Treatments followed by the same letter did not differ according to the Kruskal-Wallis test $(p \leq 0.05)$. The significance indicated is that of each compartment (root, shoot, leaves, and total dry weight). In italics: root/shoot ratios. Those values that differ significantly from controls according to the Kruskal-Wallis test $(p \leq 0.05)$ are marked with asterisks. B: clone B. Y: clone Y.

Fig. 4 Hydraulic conductivity per unit stem length (kl), hydraulic conductivity per unit xylem area (ks) and hydraulic conductivity per unit leaf area (kl) of two willow clones growing under different water regimes: FC (field capacity); F (flooding) and D (drought). Treatments followed by the same letter did not differ according to the Kruskal-Wallis test $(p \leq 0.05)$.

Fig. 5 Number and area of vessels in plants of clone B and clone $Y$ under different water regimes: FC (field capacity); F (flooding) and D (drought). Treatments followed by the same letter did not differ according to the Kruskal-Wallis test $(p \leq 0.05)$. 
Fig. 6 Principal Components Analysis (PCA) of the different variables measured in the experiment. The variables included in the PCA were: RSR (root to shoot ratio); NV (number of vessels); AV (area of vessels); kh (hydraulic conductivity per unit stem length), ks (hydraulic conductivity per unit of xylem area); kl (hydraulic conductivity per unit leaf area), NBL (number of basal leaves); WC (water consumption); TLA (total leaf area); TDW (total dry weight); Hf (final height, day 41); gs (stomatal conductance measured on day 41). 


\section{Page 23 of 31}

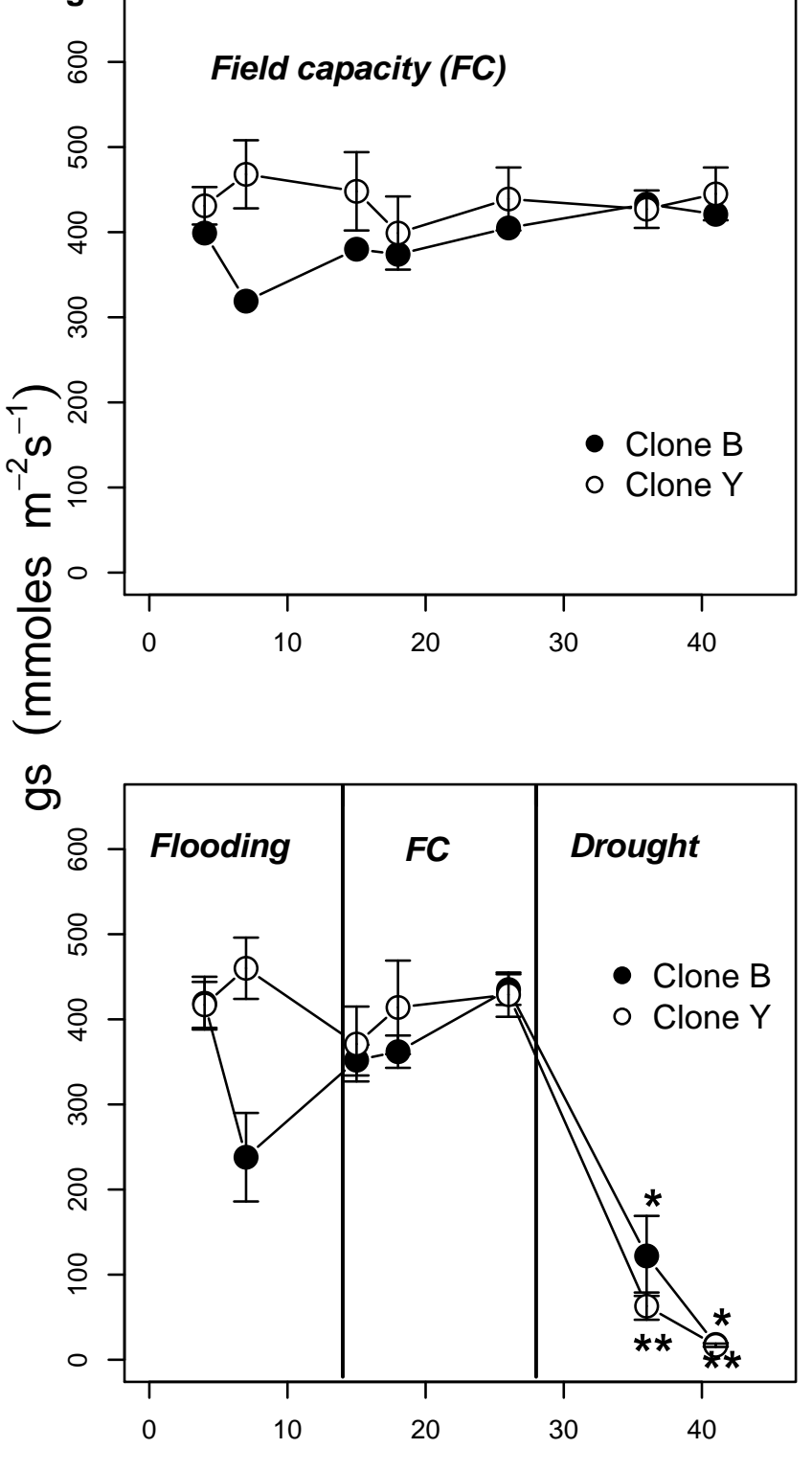

FlG. 1
Canadian Journal of Forest Research
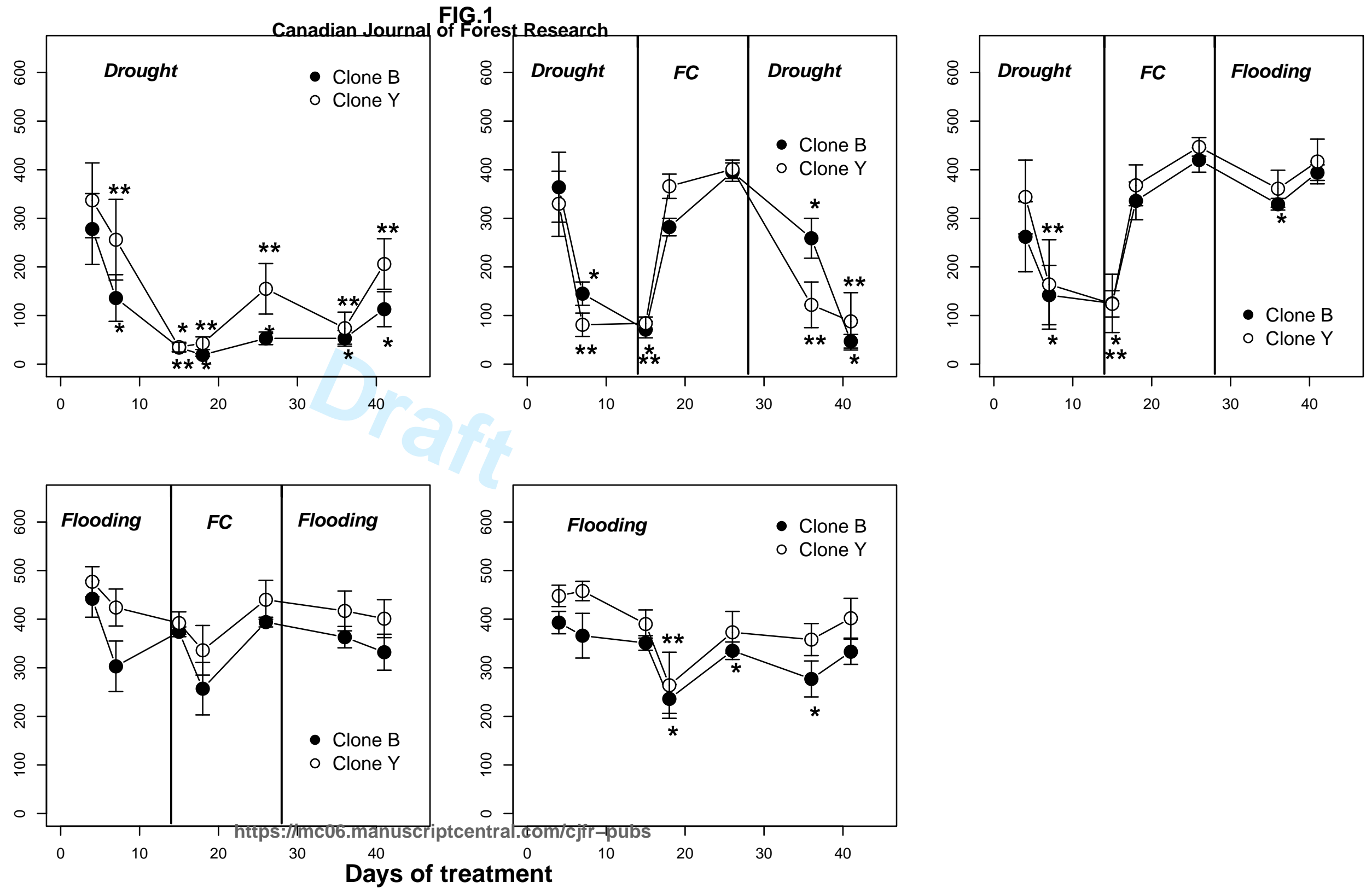


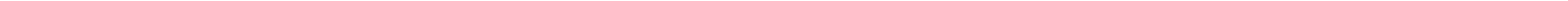


FIG.3

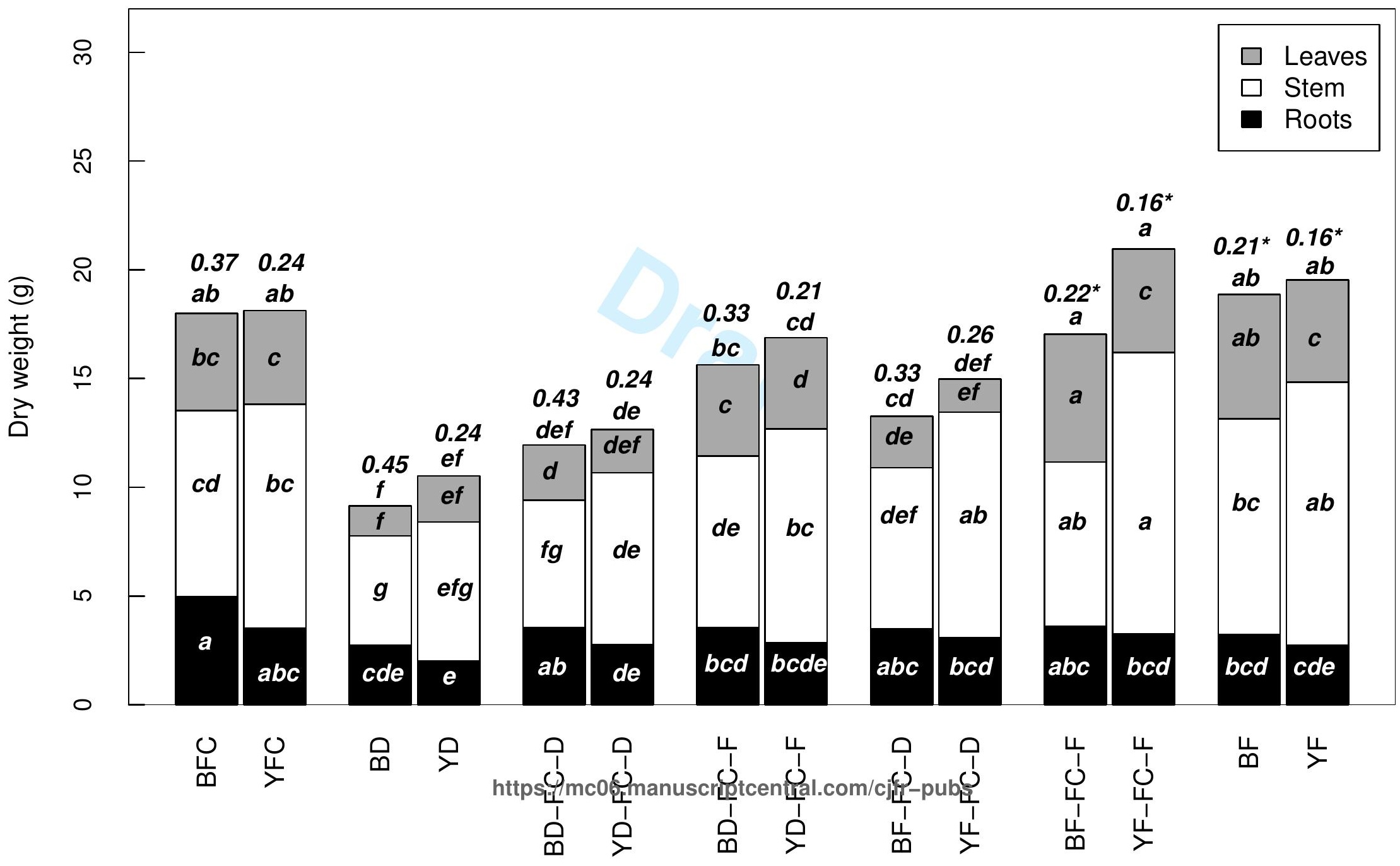




\section{T⿱宀八}

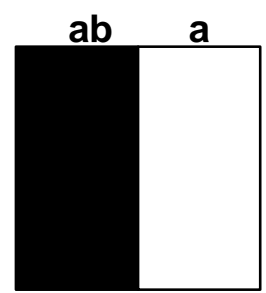

Field Capacity

$a b$

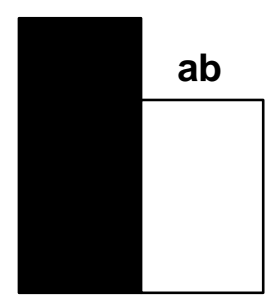

Field Capacity

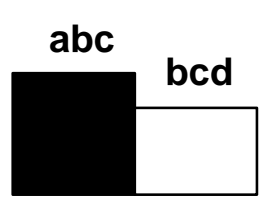

Drought

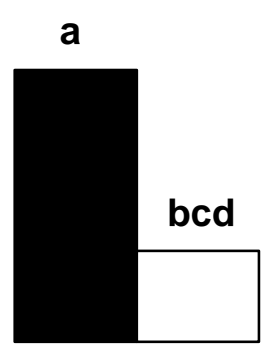

Drought

a

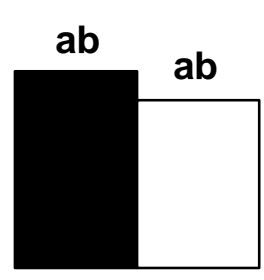

Field Capacity $a b c$

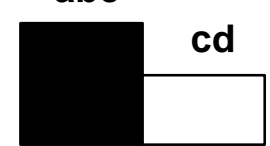

D-FC-D

$a b c$

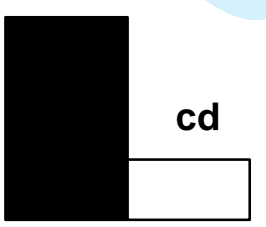

D-FC-D

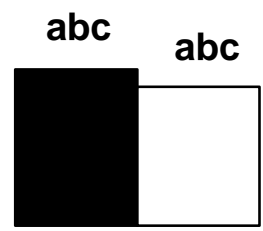

D-FC-F

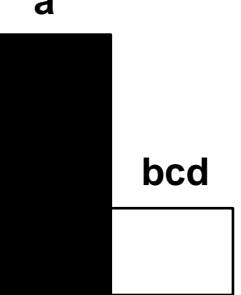

Drought

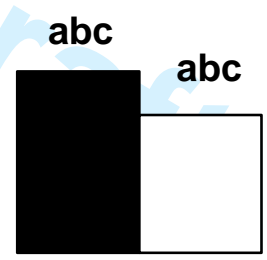

D-FC-F abcd

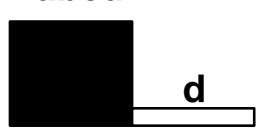

F-FC-D

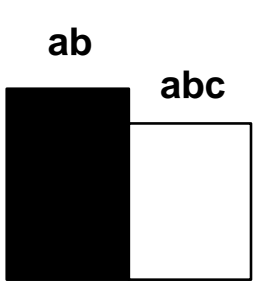

F-FC-F

Page 26 of 31

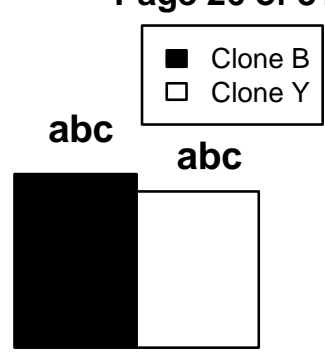

Flooding

ab

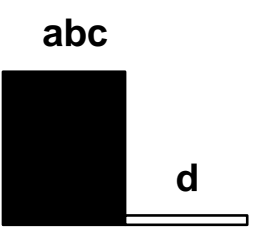

F-FC-D

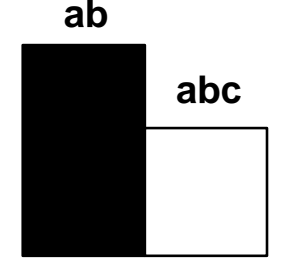

F-FC-F

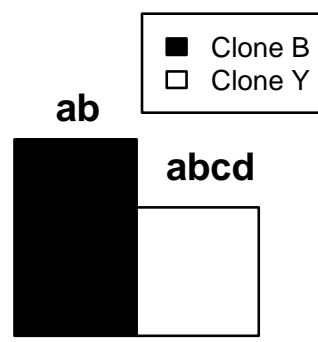

Flooding $a b c$

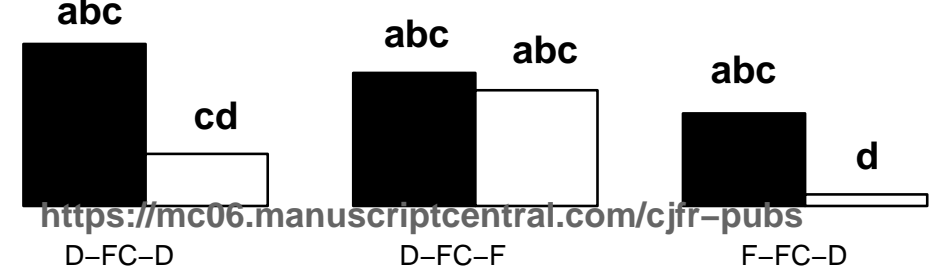

ab

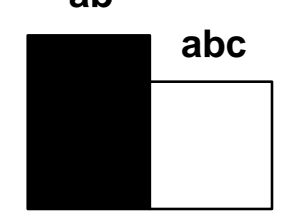

F-FC-F
- Clone B
$\square$ Clone Y

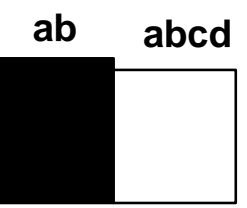

Flooding 

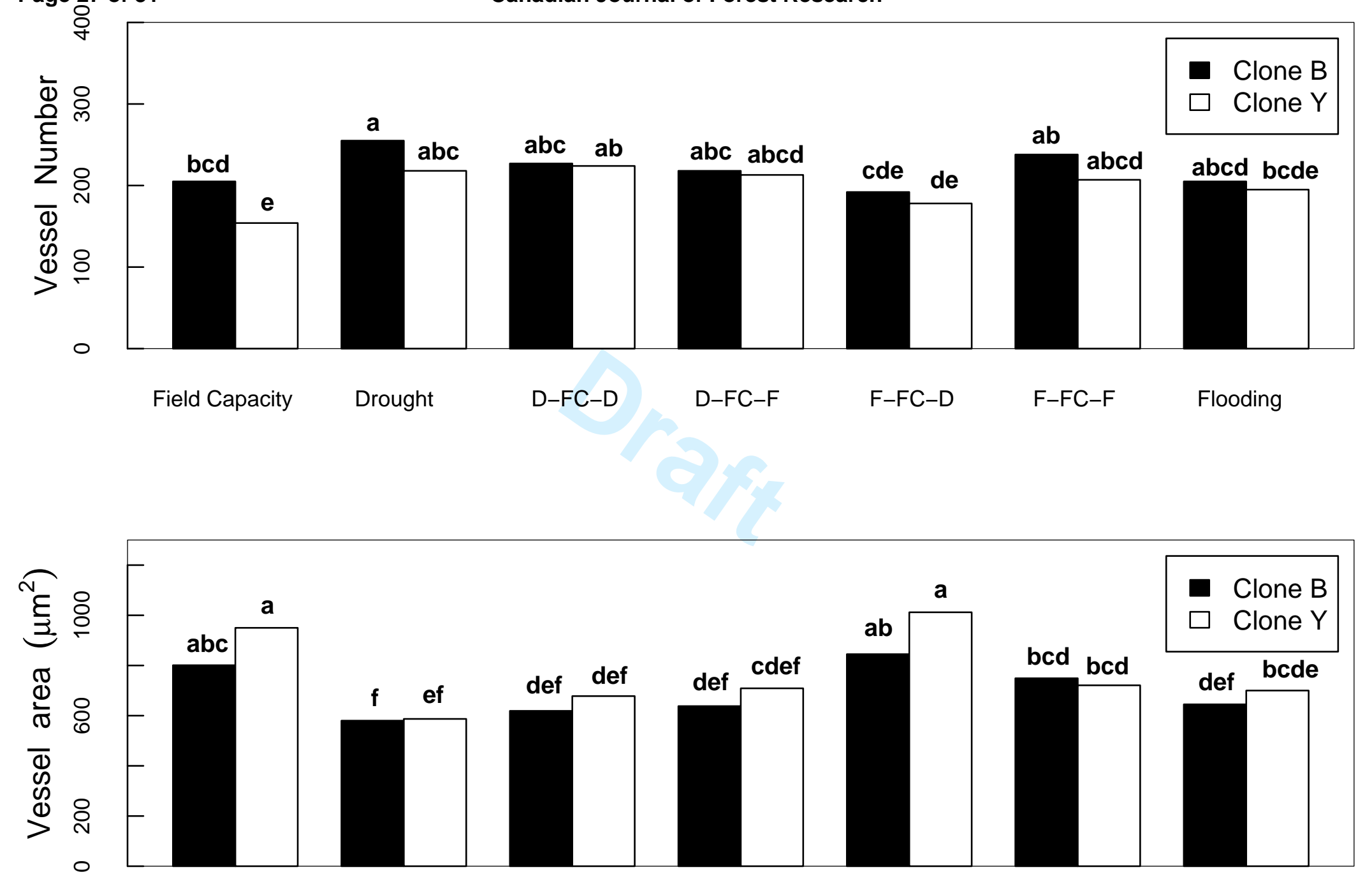

Field Capacity 


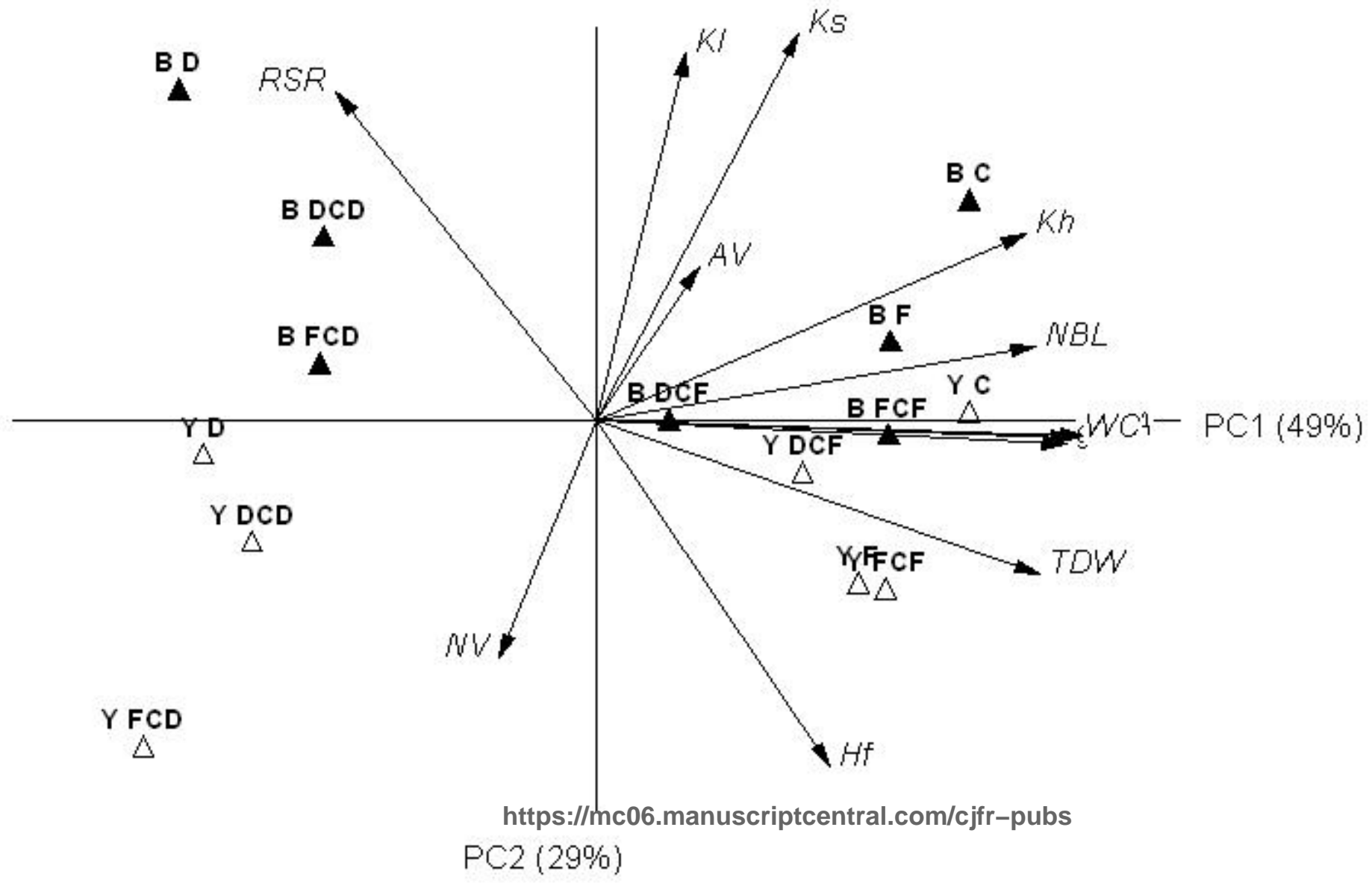



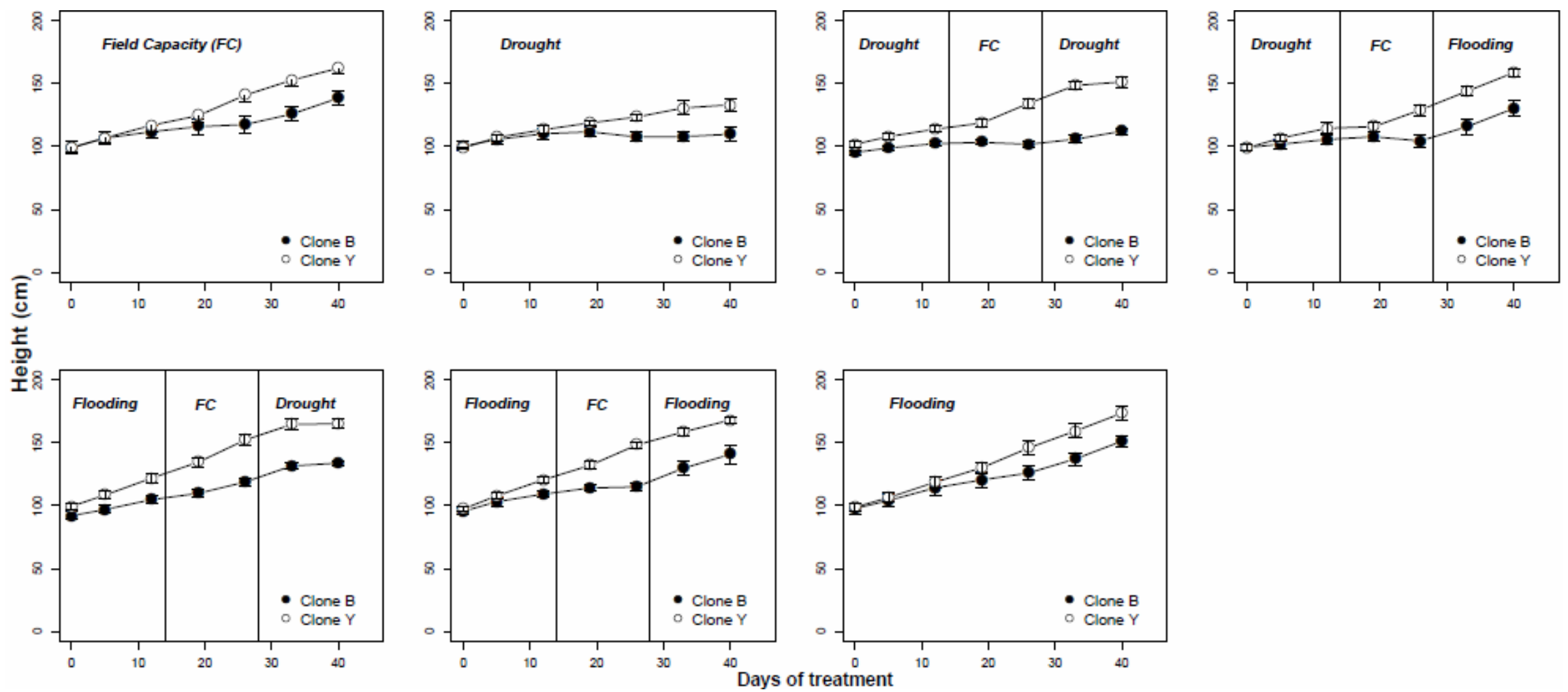

S. Fig. 1 - Height of plants of two willow clones under different water regimes and their combinations: FC (field capacity); F (flooding) and D (drought). Vertical bars: standard error of the mean. 

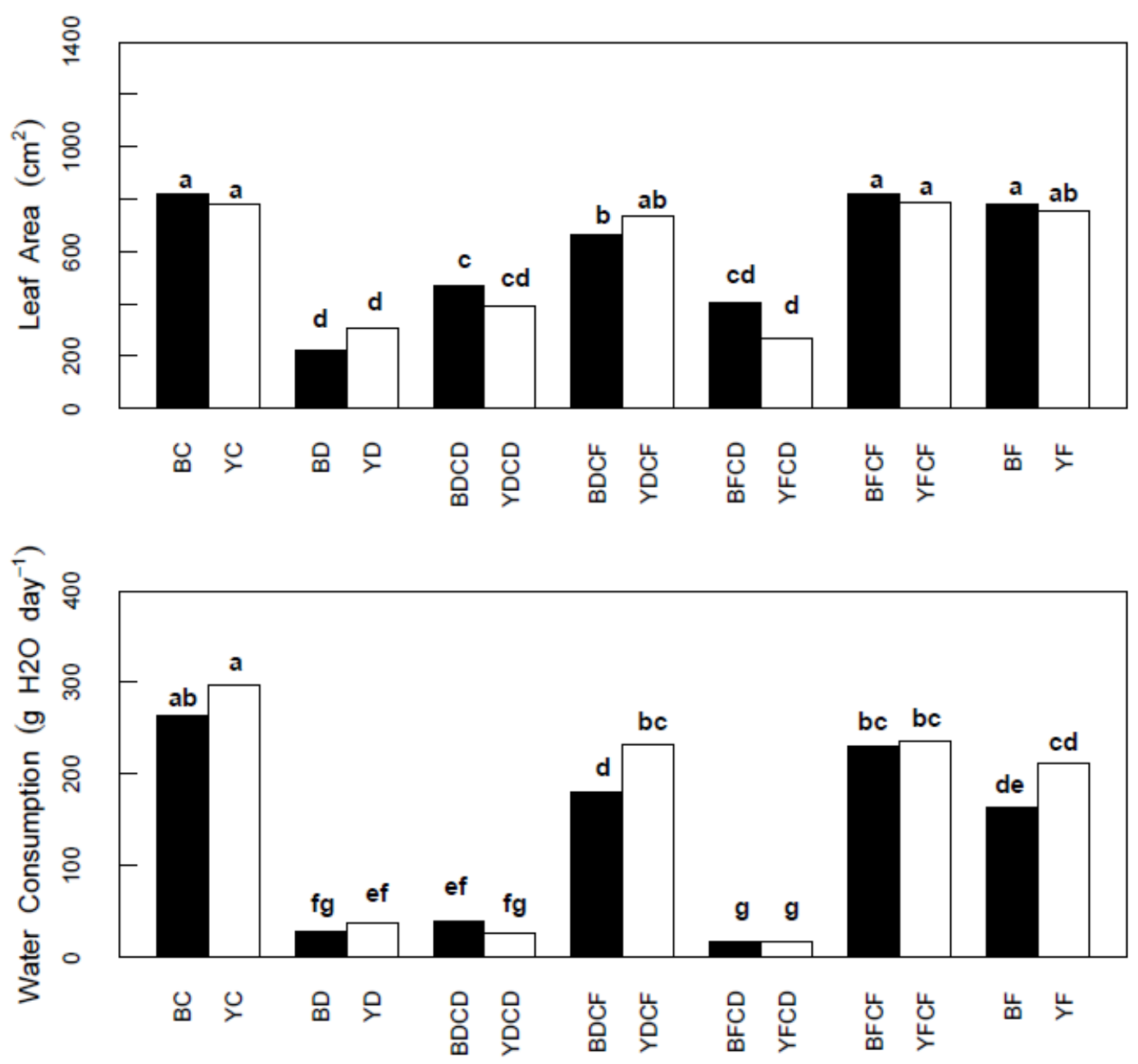

S. FIG.2 - Leaf area and water consumption in two willow clones under different water regimes: C (field capacity); F (flooding) and D (drought). Black: clone B, White: clone Y. Treatments followed by the same letter did not differ according to the Kruskal-Wallis test $(p \leq 0.05)$. 

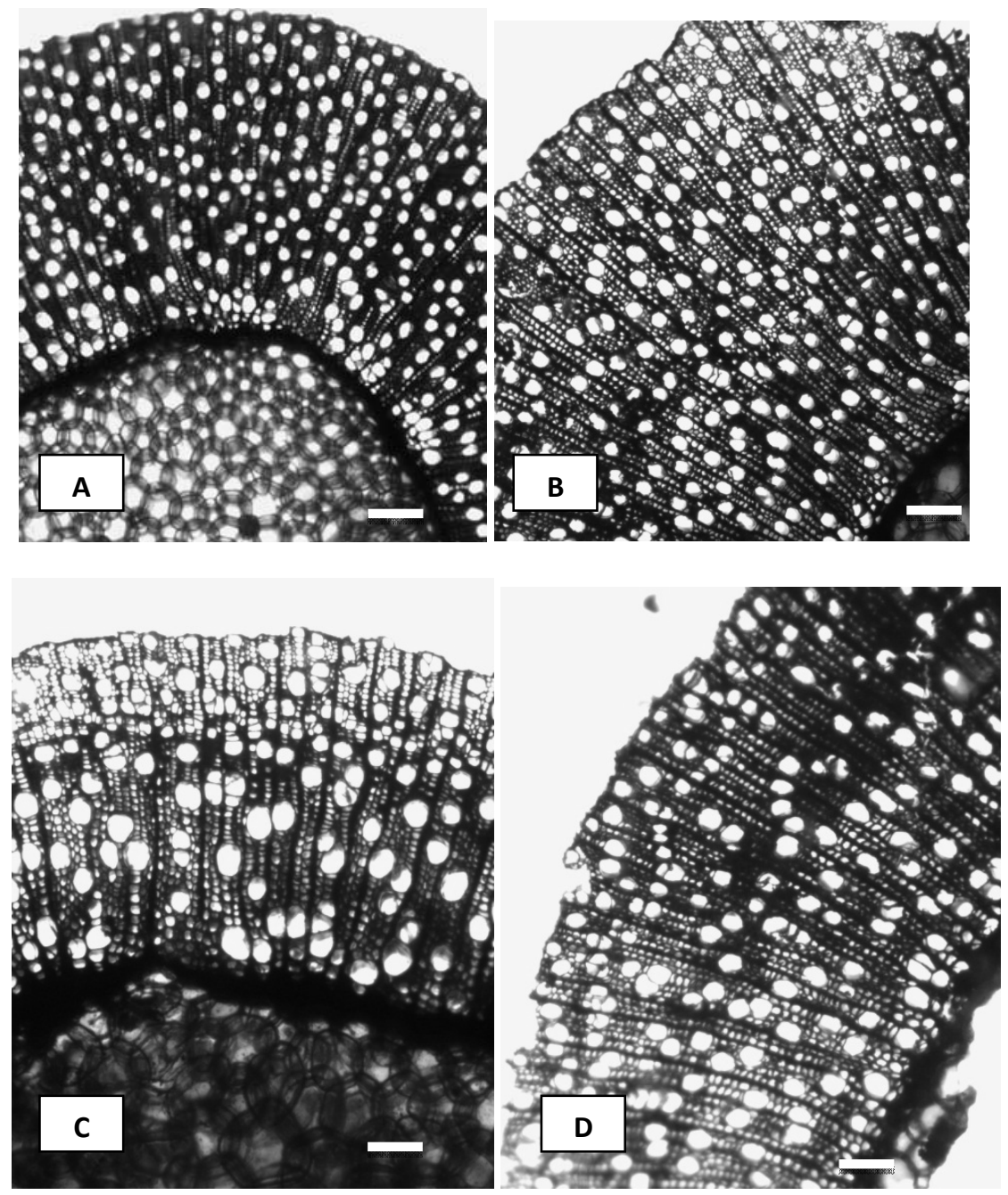

Supplementary Figure $\mathbf{3}$ - Images of the vessels in the control treatment (Panel A clone $B$, panel $B$ clone $Y$ ) and in the continuous drought ( $D$, panel $C$ clone $B$, panel $D$ clone $Y$ ). Scale bar: $50 \mu \mathrm{m}$. 